\title{
"Temprano hay que ser hombre". Masculinidades, educación sexual y confesión en Amor Mundo de José María Arguedas
}

\author{
"Early must be a man". Masculinities, sexual education and \\ confession in José María Arguedas' Amor mundo
}

\author{
EduARDo HuAYTÁN \\ Purdue University \\ ehuaytan@purdue.edu
}

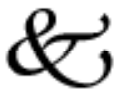

\begin{abstract}
Resumen
El propósito de este artículo es entender la función de la sexualidad para la construcción de las identidades masculinas en Amor mundo (1967) de José María Arguedas. Identifica la masculinidad subalterna del niño Santiago y la masculinidad dominante del hacendado don Guadalupe. Propone que la interacción de ambos personajes es dada a través de una dinámica aprendiz (Santiago)/ maestro (don Guadalupe). Intenta resolver cómo estas identidades son jugadas básicamente en el terreno de las relaciones sexuales. Además cómo la sexualidad masculina establece relaciones con el poder y el placer, con las identidades femeninas, con el fantasma de la culpa y con la confesión como acto edificante.
\end{abstract}

Palabras claves: sexualidad, masculinidad subalterna, masculinidad dominante, identidades femeninas, confesión. 


\begin{abstract}
The purpose of this article is to understand the role of sexuality for the construction of masculine identities in Amor mundo (1967) by José María Arguedas. It identifies the subaltern masculinity of child Santiago and the dominant masculinity of landowner Don Guadalupe. It proposes that the interaction of the two characters is given through a novice (Santiago)/ master (Don Guadalupe) relationship. It tries to determine how these identities are played primarily in the field of sexual intercourses. In addition how masculine sexuality establishes relationships with power and pleasure, with female identities, with the ghost of guilt, and confession as edifying act.
\end{abstract}

Keywords: Sexuality, Subaltern masculinity, Dominant masculinity, Feminine identities, Confession.

Recibido: 26/1/16 Aceptado:19/2/16

Agua (1935) fue el primer conjunto orgánico de cuentos publicados por José María Arguedas. Cuatro novelas y treinta y dos años después decide apostar por un nuevo grupo de cuentos en el que retoma algunos temas ya esbozados desde el primer libro y ahonda en otros que fueron siendo perfilados en sus novelas. ${ }^{1}$ Esta vez bajo el título de Amor mundo (1967) — "El horno viejo", "La huerta", "El ayla", "Don Antonio"-, Arguedas vuelve a retratar el microuniverso de la hacienda andina y la imagen sombría del hacendado desde la perspectiva de un personaje adolescente, Santiago, versión equivalente al niño Ernesto de Agua. A diferencia de este, Santiago no solo será testigo, sino actor relevante en las dinámicas sociales de ese pequeño mundo de jerarquías. A su vez, otra diferencia notable en relación a los primeros relatos es el desarrollo temático del sustrato sexual y sus variados significados.

En Amor mundo el sexo es el lugar del placer y la culpa, pero también del poder sobre las mujeres y otros hombres de menor jerarquía. Dicho de otra forma, los abusos del poder mediados a través del ejercicio de la violencia, varias veces contra la voluntad de uno de los participantes, se manifiestan en

1 Sin embargo, Carmen María Pinilla (2011) enumera los cuentos que publicó entre 1935 y 1967 en revistas y que presentó a diversos concursos. En su mayoría estos serán reunidos junto a los cuatro cuentos orgánicos de Amor mundo. De otro lado, Galo González afirma que: "después de la publicación de El sexto (1961) los episodios eróticos se incrementan en número, posiblemente porque el autor ha logrado ya la expresión cruda de realidades crudas [sic]. El comportamiento de los personajes masculinos ante la mujer resulta más impetuoso. La mujer ya no es adorada ni distante, sino maltratada y accesible en los prostíbulos" (1990: 65). 
las prácticas sexuales; a su vez, estás prácticas definen y refuerzan la identidad masculina dominante, encarnada por el hacendado. En Amor mundo, Santiago es testigo y varias veces actor de escenas sexuales que lo hacen oscilar entre el placer y la culpa. Santiago intenta aprender la lógica final de la sexualidad a lo largo de los cuatro cuentos; sin embargo, el entendimiento de ella se le mostrará esquivo y vano, casi sin resolución. El sexo será esa actividad que lo perturba y lo atrae. Sin en Agua la masculinidad se construye en clara oposición, odio y enfrentamiento ante la figura del hacendado; en Amor mundo, la masculinidad se juega en otra de sus aristas, la capacidad para ejercer potencia sexual y mostrar poder de dominio sobre la mujer —al hacerla gozar, sufrir o las dos cosas al mismo tiempo-; es decir, en el juego de la virilidad y las anulaciones de la economía afectiva. ${ }^{2}$ Como lo ha señalado Sara Castro-Klaren: "Los personajes de Arguedas jamás pasan por la experiencia del amor romántico. Los héroes se extasían en la intensidad de la conquista política o de la visión mística" (1983: 57).

En este trabajo me interesa delinear la masculinidad subalterna de Santiago y otros personajes como don Antonio, pero también la masculinidad dominante del hacendado, el caballero/ don Guadalupe. Intento resolver cómo estas identidades son jugadas básicamente en el terreno de la práctica sexual. Y cómo es que el sexo establece conexiones con el placer y el poder, con el fantasma de la culpa - la confesión y el tabú- para delinear la identidad masculina. Los cuentos de Amor mundo, como ha señalado Gracia María Morales (2006), se entrelazan en un hilo narrativo que permite una lectura independientemente $o$ en conjunto, como una nouvelle. Si es visto como un único relato, la maquinaria del sexo y el deseo empieza a moverse desde la primera escena de "El horno viejo". En este, el caballero — de quien se revelará el nombre en el relato siguiente, "La huerta"-, toma a Ernesto de la cocina para llevarlo a presenciar el encuentro sexual con doña Gudelia. El caballero será el maestro que hace de Santiago su aprendiz en la enseñanza del sexo. Intentará despertar su sexualidad y una forma de conducirse como hombre en el mundo (de la hacienda). Luego, en "La huerta", el despierto deseo sexual del adolescente tendrá un foco independiente de acción, fuera de la mirada de El caballero, a través de los encuentros con Marcelina, la lavandera. En ambos el gran conflicto irresoluble estará entre el goce, la culpa y la expiación de esta en la confesión. No obstante, en "El ayla" se mostrará una sexualidad alternativa, la sexualidad "sana" de los indígenas, a la cual Santiago no podrá acceder por ser blanco. Finalmente, "Don Antonio" será un cuento concluyente, Santiago, en diálogo con el chofer

2 En un artículo publicado en el 2013 exploré la construcción de las identidades masculinas en el cuento "Los escoleros" de Agua. Ver bibliografía. 
don Antonio, fracasará en el intento de encontrar una explicación tranquilizadora sobre el sexo. No hallará redención del conflicto que lo atraviesa y este definitivamente terminará afectando la constitución de su naciente hombría y virilidad, el tránsito de niño-adolescente a hombre.

\section{Educación y despertar sexual en "El horno viejo"}

La estudios sobre José María Arguedas ha establecido diferentes dualidades antagónicas en su narrativa —indio/ hacendado, comunidad/ hacienda, sierra/ costa, tradición/ modernidad, quechua/ español, mundo indígena/ mundo occidental-, a estas dicotomías ampliamente difundidas es pertinente sumar las siguientes: masculino/ femenino de Anne Lambright (2006) y ágape(amor)/ eros(sexo) de Galo González (1990). ${ }^{3}$ Lambright desarrolla la contraposición de lo masculino/ femenino para proponer lo femenino en la narrativa de Arguedas como un código amplio en el que cabe todo aquello expelido por poder del mundo patriarcal: la mujer, el indio, la cultura andino-indígena, la naturaleza, la oralidad, el quechua. Sin embargo, para tener una mirada más amplia sobre aquella dualidad de lo masculino/ femenino es necesario visitar el lugar de las masculinidades, tema que gran parte de la crítica hasta hoy no ha considerado en el análisis de la narrativa de Arguedas. ${ }^{4}$

Parte del sistema patriarcal se estructura en la práctica cotidiana de las masculinidades y estas se organizan a través de la hombría y la virilidad. Entiendo la masculinidad como una configuración de prácticas dentro de un sistema de relaciones de género. En ese sentido, no existe una sola forma de masculinidad sino varias en tiempos y espacios culturales específicos; es decir, y en tanto se elabora y actualiza en actos "performativos", para intentar definirla se necesario considerar los factores de clase, raza, edad u orientación sexual (Badinter 1993, Bourdieu 2000, Fuller 2001). Los estudios sobre masculinidades han

3 González clasifica los pasajes amorosos y eróticos en las novelas y cuentos de Arguedas a partir de dos formas de encarar la sexualidad: el ágape y el eros. El ágape se caracteriza por la idealización, divinización y marianización de la mujer en una relación que aspira a lo celestial y se caracteriza por una distancia insalvable entre amante y amada: "La mujer no deja su pedestal para completarse con el hombre” (1990: 32). Frente a esta concepción se haya el eros, el deseo que "Se lanza al desenfreno de la pasión carnal y encuentra en la mujer la satisfacción de sus instintos" (1990: 32). Este placer es efímero y causa terror, culpa y repugnancia (1990: 33). Los hombres y los jóvenes padecen de un puritanismo extremo; por tanto, a las mujeres que son accesible a los deseos del hombre se las compagina con el demonio: "La orgía demoniaca del acto sexual termina convirtiendo al hombre y a la mujer en animales repulsivos" (1990: 33).

4 Un par de casos de excepción son "'Un sexo desconocido confunde a esos'. Masculinidades y conflicto social en El zorro de arriba y el zorro de abajo" de César Romero (2013) y "Raza, género y hombría en la obra temprana de Arguedas" de Margarita Saona (2013). 
organizado tipos que se definen y constituyen mutuamente. A grandes rasgos pueden ser dominantes, hegemónicas y subalternas (Conell 1997, Kaufman 1995, Fuller 2001). Además, para entenderla de mejor manera es necesario diferenciar dos conceptos que se articulan en ella: virilidad y hombría. Mientras la virilidad se representa como natural, universal e invariable, como el núcleo básico de la masculinidad: sexualidad activa, potencia sexual, capacidad penetrativa y fuerza física; ya que el gran porcentaje de hombres nace con órganos sexuales masculinos y posee, por lo general, mayor grado de fuerza en relación a su par femenino; la hombría se representa como un producto cultural, en el cual los significantes claves son la fortaleza, el vigor, la valentía y la honra. Es un estatus que todo varón debería alcanzar para ganar el título de hombre de bien, respetable, honorable. Se confirma a través del reconocimiento del grupo de pares y del mundo institucional (Fuller 2001: 28-29).

En Amor mundo, a diferencia de Agua o Los ríos profundos, las prácticas de la sexualidad son una piedra angular para la construcción de la identidad masculina adolescente; por tanto, es necesario enfocar de modo más detallado la performance de la virilidad, pues el cuerpo y las prácticas sexuales como instrumentos de poder también son centrales para la definición del género. La sexualidad es central para la definición de la identidad de género, una práctica $y$ discurso que no puede entenderse completamente sino es a través de las relaciones de poder. En el primer cuento, "El horno viejo", el caballero busca despertar la virilidad de Santiago; el modo de sus acciones y el rol que asume y delega en él se asemejan a los roles maestro/ aprendiz de la tradición de novelas pornográficas francesas e inglesas del siglo XIX; a su vez, la estructura misma del cuento sigue, en síntesis, el modelo de aquellas. Para Jørgen Johansen (2004) este tipo de novelas solo pudieron proliferar en sociedad de estructuras jerárquicas. Precisamente, el mundo de la hacienda del Ande en la primera mitad del siglo XX y el rol que los hacendado, sirvientes y peones desempeñan se organizan a partir de ese tipo de relaciones. El individuo masculino se conducirá de cierta manera bajo estas estructuras:

Le monde becomes a theatre, and the individual actor's task is to direct himself as shrewdly and charmingly as possible in order to add to his amour-propre, a term not easily translated since it means, at least, selfishness, vanity, sense of honor, proper pride, and self-esteem. (Johansen 2004: 42)

Arguedas al parecer barajó más de un título para el grupo de cuentos que venía escribiendo desde la segunda mitad de la década de 1960. Finalmente opta por titular al conjunto Amor mundo. Con este título pareció entender la imagen del espacio de la hacienda como un espacio autónomo y cerrado o me- 
jor aun como un escenario teatral para realizar la performance de la sexualidad y la identidad masculina. ${ }^{5}$ En este mundo el hacendado, el caballero/ don Guadalupe, encarna bien los valores individuales afrancesados: egoísmo, vanidad, orgullo y un amor propio intensificado que pisotea al de los demás, mujeres y hombres carentes del poder. Johansen dice que en este tipo de literatura: "the erotic scene is the most important, and to play one's part beautifully means primarily to be an outstanding lover and seducer, to be able to awake the desire of others" (2004: 42). En "El horno viejo" se narran, omniscientemente y son descritas en detalle, tres escenas de encuentros sexuales: 1) El caballero/ doña Gabriela y Santiago de voyeur-masturbador; 2) El burro/ la yegua; dos voyeurs involucrados, Santiago y la joven hija de hacendado, pero en diferentes niveles, la joven mira a los animales y Santiago la mira a ella o su goce y perturbación. 3) El caballero/ doña Gudelia; Faustino/ la prostituta Santanina y Santiago una vez más como observador. ${ }^{6}$ Además, siguiendo el trazado de las novelas pornográficas, el caballero/ Don Guadalupe asume el papel del hombre que busca despertar y encender la pasión de sus amantes casadas como en Santiago. Los fines son diferentes, con las amantes se busca ejercer el poder y con el niño educarlo en esta lógica.

Johansen también describe el carácter educacional de las novelas pornográficas: "The educational character of the novel is stressed by the space devoted to lecturing the novice; in fact the sexual activity is most often a practical demonstration of what has already been explained verbally" (2004: 43). En Amor mundo la distribución de estos roles de maestro/ aprendiz son asumidos por el caballero (el maestro) y Santiago (el aprendiz). El fin principal no es el sexo y el placer transgresor, fuera de la norma social como en las novelas europeas, sino lo que está detrás es el modelado de la identidad de género masculina. Dicho de modo simple, el sexo es un intermediario, un ritual, para alcanzar la virilidad que modela parte de la masculinidad de Santiago. ${ }^{7} \mathrm{Al}$ inicio de "El horno

5 Al parecer el primer título que luego descartaría fue Hervores. En uno de los diarios de El zorro de arriba y el zorro de abajo, Arguedas dice: "Debo al auxilio de la Dra. Lola Hoffman el haber escrito desde el capítulo XX de Todas las sangres hasta la última línea de los Hervores” (1983: 239).

6 En los demás cuentos no se dará este número de escenas ni de participantes, pero las escenas sexuales seguirán estando en el núcleo del relato. En "La huerta" se desarrollan los dos encuentros sexuales entre Santiago y la lavandera Marcelina. En "El Ayla" se describe el ritual sexual de los jóvenes indígenas, haciéndose un zoom de una pareja en particular. En "Don Antonio" están las referencias a las experiencias del chofer ante las preguntas de Santiago y una visita a un prostíbulo costeño.

7 Para David Durán en el "Horno viejo”, “el patrón lo lleva [a Santiago] a ver el modo en que goza, dejando a Santiago impotente y culposo" (2014: 115). La finalidad es "la generación de la impotencia del ciervo" (2014: 115). No coincido con esta lectura, más bien, leo una finalidad educativa en ese proceso. El gamonal apuesta por ceder la posta de la masculinidad dominan- 
viejo", Santiago es sacado de la cocina — un espacio altamente femenino que comparte con la sirviente Facunda y la cocinera Cayetana-, para emprender el viaje hacia la virilidad. Ante la pregunta de donde es llevado el caballero responde: "A donde has de ser hombre esta noche" (169). Luego le pregunta su edad y Santiago responde: "El 17 de febrero cumplí nueve" (169); el Caballero replica: "Temprano hay que ser hombre" (169). En esta primera excursión se dirigen a la casa de la tía política del caballero, doña Gabriela. El maestro busca un aprendizaje y casi instantáneo en el niño: "-iHáblale, muchacho; que vea que ya eres hombre!” (171). No existe explicación verbal teórica previa. Líneas más adelante empieza la lección. El caballero le pide la mirada sobre lo que va a hacer y alumbrando la escena con la luz de un fósforo:

—Me desvisto- dijo el hombre.

Prendió un fósforo.

—Mira, Santiago— dijo.

Sólo un calzoncillo largo le cubría las piernas.

—Ahora me acuesto. Ahora oyes. Si quieres ver, ves. Aquí tienes el fósforo. (171)

La amante de turno es la esposa de su tío carnal, doña Gabriela, quien se resiste por a la presencia de Santiago. En esta relación se conjugan exhibicionismo, infidelidad y abuso. Si estas actividades empiezan a ser clasificadas como patológicas en el siglo XIX en tanto atentan contra las relaciones heterosexuales basadas en la economía doméstica y la reproducción de la familia burguesa (Foucault 1998); en la sociedad andina regida por el sistema de hacienda, estas prácticas más bien refuerzan el dominio de sus dirigentes encarnados en el hacendado y su masculinidad dominante; en este sistema un grupo muy reducido de hombre, la mayoría de ellos blancos o mestizos, se distribuye el poder y lo detentan. ${ }^{8}$

te a este niño que si bien no es uno de los suyos, tampoco es indígena, está más próximo a su posición en el tablero social.

8 Ruiz Bravo y Eloy Neira (2001) en un trabajo sobre la masculinidad de los patrones de hacienda en todo el Perú, describe las particularidades del patrón de la sierra sur. En la memoria de los pobladores estos son recordados como encarnación de todo mal: abusivos, poderosos, que gobierna sus dominios sin ningún límite ni control. Este tipo de masculinidad es plausible de ser descrita como dominante. Connell (1997) la define como aquella que sostiene y usa los medios de la violencia. Dos patrones se derivan de esta situación: en primer lugar, muchos miembros de grupos privilegiados usan la violencia para sostener su dominación. Hay una justificación, se está ejerciendo un derecho, se sienten autorizados por una ideología de supremacía. Segundo, la violencia llega a ser importante en la política de género entre los hombres. La violencia puede llegar a ser una manera de exigir o afirmar la masculinidad en luchas de grupo. 
La primera prueba resulta devoradora para el niño: "comenzó a tragar la oscuridad como si fuera candela. Se tocó las rodillas que estaban temblando. No estaban calientes" (171). Ante la resistencia de doña Gabriela por la presencia disruptiva de Santiago, el caballero amenaza con gritar para despertar a los hijos que se encuentran en la otra habitación. Sin en el cuento "Warma kuyay", incluido en Agua, la escena de la violación de Justina por el patrón es dicha pero no descrita, aquí sucede todo lo contrario. La performance violenta del gamonal ya no es mostrada en los espacios abiertos de la hacienda, sino en la intimidad de una habitación matrimonial profanada. En su réplica el caballero demuestra que no le asusta la amenaza de la mujer: "El hombre no se embarra con estas cosas, al contrario" (172). Castro-Klaren cree que el caballero "quiere ser visto para escandalizar" (1983: 61). Más bien la lógica de la acción del caballero parece no solo querer liberar el escándalo sino develar en la exhibición el núcleo de su virilidad, el pene y la capacidad penetrativa sobre la mujer, y con esta acción el refuerzo de su masculinidad. De otro lado, en la mujer no hay lugar para el placer: "ella lloraba mucho y rezaba" (172). Foucault afirma que la sexualidad es "un punto de transferencia especialmente denso para las relaciones de poder: entre hombres y mujeres, jóvenes y adultos, padres e Hijos, curas y feligreses" (103). Precisamente esta relación de poder alrededor de prácticas sexuales es la que se pone en doblemente en juego: entre el caballero y doña Gabriela, entre el caballero y Santiago. Además, la lección del maestro incluye un tratamiento rudo y al mismo tiempo seductivo. Este programa incluye cuatro elementos:

1. the infliction of pain in order to submit the victim to the authority of the parental figure $[\ldots] 2$. the awakening of the subject's sexual desire against her own will, her decency, and feelings of shame and guilt; 3 . her exposition to sexual activities by others, and by the tutor herself; and 4. the cramming of the heroine with the libertine doctrine by means of lectures. (Johansen 2004: 45-46)

En esta primera prueba, Santiago es un voyeur que no puede evitar llorar y gozar al mismo tiempo: "Entonces el chico sintió que se le empapaba el rostro. Casi al mismo tiempo, su mano derecha resbaló hasta su propio vientre helado. No pudo seguir de pie empezó a rezar desde el suelo, el cuerpo helado sobre la tierra" (172). Lo asalta su impronta educativa católica: "Perdón, Mamacita, Virgen del cielo, Virgencita linda, perdón...” (172). Sin embargo, al la par de la oración se da la masturbación. Santiago ha caído y el deseo ha sido encendido contra su propia voluntad hasta hacerse visible en su propia temblorosa voz. El maestro se percata: "- -Tu voz es de que estás gozando, oye, aunque estás rezando" (172). Luego de esta primera lección le advierte que vendrán más: “Mañana o pasado será mejor. En el horno viejo”" (172). 


\section{El fracaso del discípulo, pecado y confesión en "La huerta"}

La finalidad de la diégesis de las novelas pornográficas es hacer del héroe aprendiz un maestro, réplica de su tutor. Propone un ciclo narrativo sin fin en el que se reproducen determinados tipo de relaciones e identidades. A diferencia del programa de estas novelas, el despertar del aprendiz en Amor mundo está plagado de conflictos, caídas y fracasos que no se resuelven. Santiago, el niño blanco sin familia, debe seguir los pasos del caballero, pues este ha decidido dar un espacio en su sitial y hacer circular un poder que siempre es distribuido exclusiva y excluyentemente en ciertos elegidos. Sin embargo, el maestro es consciente de su fracaso al final de "El horno viejo". Dado un momento de la orgía, Santiago es puesto a prueba al ser pedido de participar; este se resiste y huye hacia la entrada del lugar, desde donde a momentos mira y oye lo que acontece dentro. Al termino de toda la escena, el caballero se topa con Santiago y se dirige a otro de los participantes para referirse al muchacho: "No es nadie, ese" (179). El joven aprendiz no ha cumplido con las expectativas trazadas en las lecciones por el maestro, por ende, no es hombre y si no es hombre no es nadie. ${ }^{9}$

Una de las finalidades cognitivas en el aprendiz es el autocontrol de la sexualidad, que debiera jugarse en un espacio sin culpas ni descontrol: "The important point is, however, that the pupil is told to show self-mastery, not to be carried away by sexual desire, but, on the contrary, to remain self-possessed even at the peak of lust" (Johansen 2004: 48). Santiago no puede alcanzar las destrezas del maestro y trasladar esa narrativa de violencia en el desarrollo de su identidad, sin embargo, en él yace inoculado un deseo intenso, poco controlable, y una culpa de igual proporción.

En "La huerta", luego de la educación sexual inicial, Santiago experimentará sus primeros encuentros sexuales. El espacio de la huerta, a diferencia del horno viejo, al inicio del relato es descrito como un lugar idílico y puro con reminiscencias al paraíso antes de la caída: "huerta de hortalizas y de capulíes [que los adolescentes pueden comer libremente por las noches] [...] Rodeaban a la huerta árboles de sauce frondosos; zumbaban con el viento o servían de reposo a los pájaros del pueblo" (182). Sin embargo, este espacio de sosiego para el niño confundido es contaminado por el sexo. Marcelina, la lavandera de un hacendado, se le acerca a Santiago para incitarlo al mostrarle "su parte vergonzosa" (184). Este no opone resistencia sino que se aproxima: "La gorda

9 No considero necesario realizar el análisis de la escena en el horno viejo, pues el esquema es similar al encuentro con doña Gabriela. La diferencia es la intensificación de la prueba, pues se duplican los actores para dar forma a una orgía en la que Santiago nuevamente toma el papel de espectador. 
Marcelina lo apretó duro, un buen rato. Luego lo echó con violencia" (184). Marcelina reconoce cierta experiencia en el muchacho: "-Corrompido muchacho. Ya sabes-" (184). Finalizado el encuentro, Santiago experimenta la suciedad y la contaminación corporal, una pestilencia que nace del sexo: "Y sintió que todo hedía" (184). Luego intentar purificarse a través de la limpieza del cuerpo y no lo consigue: "No pudo lavarse. Se restregaba la mano y a cara con la brillante arena del remanso [...] Pero el muchacho seguía recordando feo la parte vergonzosa de la mujer gorda; el mal olor continuaba cubriendo el mundo" (184). Rocío Silva-Santisteban y Francesca Denegri, a partir de la lectura del epistolario de Arguedas que puede ser aplicado a estos relatos y otros textos de ficción, dicen:

el acto sexual es visto como un acto que, sino produce temor, produce asco al mundo y, por lo tanto, la atmósfera siempre negativa de ese acto - aunque hay excepciones - se vincula directamente con el infierno en su versión metafórica pero también cristiana: el acto sexual corrompe el alma. (2005: 310)

Arguedas a lo largo de "La huerta" se vale de diversas antítesis religiosas —cielo/infierno, suciedad/ pureza, pecado/ confesión—, para describir estos encuentros. Líneas arriba acoté que el ambiente de la huerta estaba cargado de significados paradisiacos, pero este espacio se ha ido tornando infernal y el alma ha caído en el pecado. Una mancha pestilente cubre al muchacho. En esta relación, Marcelina —quien es descrita como "borracha" por el cura del pueblo, quizá como metáfora de la mujer embriagada por deseo- es la que toma un rol activo, ella es quien "lo aprieta" y "lo hecha con violencia". Si bien Santiago ya se encuentra en el performance de una virilidad, naciente, esta jamás alcanzará el rango de la virilidad del hacendado; la suya será infraviril en relación a la de aquel. Por tanto, su masculinidad se halla en los rangos de la subalternidad. Norma Fuller dice que "Toda versión de las masculinidades que no corresponda a la [hegemónica] o dominante sería equivalente a una manera precaria de ser varón, que puede ser sometida al dominio por aquellos que ostentan la calidad plena de hombres." (2001: 24). Además añade: "lo hegemónico y lo dependiente se definen y constituyen mutuamente [...] para poder definirse como un varón logrado, es necesario contrastarse contra quien no lo es" (2001: 24). Santiago no es un hombre logrado en el contexto específico del mundo de hacienda y en el horizonte de la masculinidad dominante que opera en ese mundo, porque no se muestra determinante, activo y violento en sus actos, no disfruta de la erótica del abuso del poder; más bien actúa desde la duda, el temor, el sufrimiento de la culpa cristiana. Como algunos críticos han mencionado, entre ellos González: "La lascivia, en la narrativa arguediana, termina en arrepentimiento del pecado. Los personajes que se acercan a la 
lascivia—pecado capital— sufren" (1990: 52). González además dice: "En Amor mundo se acentúan los actos eróticos asociados con lo pecaminoso y aun lo diabólico. El muchacho Santiago [...] siente horribles ganas de rezar" ${ }^{10}$ (1990: 82).

Un asunto en el que González no repara además del acto de rezar es la importancia de la confesión como expiación del pecado y su relación con la normatividad del sexo. Para Michael Foucault en las sociedades occidentales prima la práctica de una scientia sexualis para decir la "verdad del sexo" (1998: 73). Y el procedimiento privilegiado para decir esta verdad fue la confesión. En la confesión es el confesor que redime, purifica, descarga de sus faltas y libera al confesado (1998: 79). Santiago decide ir a los pies de la montaña Arayá para encontrar alguien que lo redima y consuele del desasosiego del sexo que atestigua y practica. Para Castro-Klaren: "En el caso del personaje-niño (Santiago, Palacitos, Ernesto), lo que moviliza sus actos es la necesidad de compenetración con el padre extraviado, con la armonía de la naturaleza, con la claridad del día y la sensual unión con los objetos mágicos y protectores" (1983: 56). En este camino hacia un ente protector andino que lo armonice, Santiago se encuentra por azar con el cura y le pide la confesión in-situ. El curo prefiere hacerlo en la iglesia, pero Santiago en su urgencia de expiación le cuenta sobre las lesiones pecaminosas que le han provocado las lecciones del hacendado y sus encuentros con Marcelina. El padre al escuchar le dice: "iConfiésate de rodillas! ¿Has fornicado con la Marcelina?" (186). Santiago no entiende el significado de esta palabra y le replica: "Estoy apestado; estoy sucio [...]". Luego de la confesión el padre le da su bendición. Sin embargo, el continúa su camino al Arayá. El problema en la confesión es que desde la instancia del confesor solo se escucha y se caya; no hay una respuesta que contenga y dé orden al caos del sexo. La verdad se le es revelada al confesor y no al confesado: "Pertenecemos [...] a una sociedad que ha ordenado alrededor del lento ascenso de la confidencia, y no en la transmisión del secreto, el difícil saber del sexo" (Foucault 1998: 39). O la verdad del confesor se reduce a corroborarle al confesado lo que ya sabe: que ha pecado. Ante este fracaso, Santiago continúa su peregrinación al Arayá para una confesión alternativa, alejada de los límites occidentales y más bien anclado en la cosmovisión andina: "Tú nomás eres como yo quiero que todo sea en el alma mía..." (187), le dirá a la montaña cuando se encuentre a sus pies.

Santiago regresa purificado, pero a la semana siguiente también regresa a la huerta, a la misma hora para volver al encuentro de Marcelina: "Y se dejó apretar más fuerte y más largamente que la primera vez, se revolcó e, igual que entonces, fue ella quien lo arrojó, y se marchó luego de mirarlo como se miran

10 Los artículos ya citados de Sara Castro-Klaren (1983) y Rocio Silva-Santisteban y Francesca Denegri (2005) también han abordado el peso de la culpa cristiana ante el sexo. 
a los huesos botados" (187). En los encuentros con Marcelina, la narración solo se focaliza en la culpa del joven, no medita la culpa de las mujeres o sus actitudes, al menos de las que son como Marcelina. Castro-Klaren dice sobre la Opa de Los ríos profundos y Marcelina: "Mientras que la animalidad que gobierna su cuerpo es responsable por su agresiva conducta sexual, esa misma bestialidad las excusa de ser 'pecadoras', ya que su idiotez las previene del poder de ejercer juicios morales y las hace un tanto sufridoras" (1983: 63). Santiago vuelve al arrollo, pero ya no se lava: "Le rendía el hedor que todo su cuerpo exhalaba" (188). Decide frotarse el rostro con hierbas aromáticas mezcladas” (188). Santiago se mueve entre una repetición compulsiva de idas a la huertas para luego ir al Arayá a limpiar su suciedad, ya no recurre a la confesión del cura: "¿Cuántas semanas, cuántos meses, cuántos años estuvo yendo de la huerta al Arayá? No se acordaba, en el camino maldecía, lloraba, prometía y juraba firmemente no revolcarse más sobre el cuerpo grasiento de Marcelina" (188).

Al final de "La huerta", Santiago cuestiona si esa sexualidad que lo perturba tiene que ver con no ser indígena: "'Será que me sucede esto porque no soy indio verdadero; porque soy un hijo extraviado de la Iglesia” (188). En este punto se empieza a insinuar que la sexualidad de los hombres blancos y mestizos está viciada y alejada de cualquier armonía. El desarrollo de esta insinuación se da en los siguientes dos relatos de la secuencia.

\section{Formas alternativas de sexualidad en "El ayla" y diálogo sin resolución en "Don Antonio"}

"El ayla" muestra una sexualidad alternativa a la practicada por los hacendados y los mestizos. Esta sexualidad se caracteriza por tener un fin eminentemente reproductivo, enmarcarse en un ritual colectivo de fertilidad, contribuyendo al mantenimiento de la comunidad. El placer como práctica individual no reproductiva parece pasar a segundo plano. Como lo ha señalado González: "Los hábitos sexuales perversos sólo suceden en personajes blancos y mestizos. Si son indios, el enfoque es positivo, ya que la pasión sexual, en el mundo indígena, se acepta como un ciclo natural de germinación" (1983: 53). Pero además, en términos de Foucault estamos frente a una sexualidad que se inserta en un "sistema de utilidad, regular para el mayor bien de todos" (1998: 34). Este bien común tendría íntima relación con la comunidad y su supervivencia, es decir, "asegurar la población, reproducir la fuerza de trabajo, mantener las formas de las relaciones sociales, en síntesis mantener una sexualidad económicamente útil y políticamente conservadora” (Foucault 1998: 50). 
En "El ayla", Santiago vuelve a ser solo un espectador en el que los límites entre los que son parte del ritual sexual y los que lo miran con pasividad yacen muy marcados: "Mestizos y señores vieron pasar por las calles, mientras anochecía, la fila del ayla, y hablaron entre ellos" (193). Esta gente piensa que estas prácticas sexuales tienen el tenor de las prácticas de don Guadalupe: "—Van a hacer sus asquerosidades en el cerro estos indios” (193). Por el contrario, Santiago, como Ernesto, ve más allá de los prejuicios hacia el indígena y entiende la lógica interna del ritual, un indígena le dice: "Por mando del corazón y por mando del gran padre Arayá jugamos; sembramos de noche" (194). En estos encuentros sexuales la violencia está ausente, más bien goza de un carácter lúdico: "Y Santiago vio que el mozo que estaba cerca de él, le alzaba el traje a la muchacha, mientras ella hacía como que se defendía, luego se quedó quieta, completamente inmóvil, mientras el joven se revolvía sobre ella" (196). Otra diferencia es la evanescencia del olor que el muchacho percibe pestilente, por tanto, el sexo ahora es limpio o adquiere una neutralidad domesticable: "Santiago observó a la pareja que estaba cerca de él, pero los gritos no le permitieron sentir frío ni olor alguno" (197). La sonoridad musical del sexo ritualizado parece aniquilar el olor de un acto contaminado en prácticas sexuales profanas.

Sin embargo, un aspecto coincidente con las prácticas sexuales que perturban a Santiago es la pasividad de las mujeres en el momento de encarar el acto. La dinámica sigue siendo: hombre/ activo; mujer/ pasiva. Aspecto que se ahondará en el discurso sobre el sexo esbozado por don Antonio. De vuelta al relato, Santiago al sentir que esa forma de llevar la sexualidad no lo mancha, intenta unirse al ritual sexual, pero es rechazado: “-Pendejo, pendejo- dijo, muy claramente otro de los jóvenes que iba encabezando la fila[...] Dejaron solo al muchacho, como una piedra caída del cielo" (197). Si a lo largo de Agua y Los ríos profundos se mostraba la excentricidad de Ernesto en los niveles sociales y étnicos, en este pasaje esa excentricidad de la identidad se traslada al plano de género, Santiago no puede encontrar un lugar para el desarrollo de una sexualidad sin conflictos. Su identidad oscila pidiendo auxilio, si no puede ser parte de un ritual avalado por el Arayá, su confesor andino, decide volver donde un confesor occidental que tampoco puede traer respuestas: "-No te mataron - le dijo el cura en el confesionario-. No te despedazaron porque creyeron que eras un animal del maldito cerro Arayá" (197). Solo por un momento, Santiago parece reconciliarse con la sexualidad: "'Se me ha ido el mal olor, creo, peso menos, creo" (197). Pero al instante las imágenes del horno viejo, la sombra de su maestro y la presencia de Marcelina regresan: "Pero como una cascada, el llanto de doña Gudelia y el de la chuchumeca [...] empezaron a sonar bajo su pecho. Los vellos de la borracha se encendían" (198). 
Bajo los senderos sin salidas de la sexualidad, Santiago decide partir a la costa con la venía de un padre ausente. En Amor mundo se suceden varios diálogos en los que Santiago se hunde más en la confusión, primero con el guitarrista Ambrosio, luego con el cura y, finalmente, con don Antonio. Mientras viajan a la costa con este último, Santiago pregunta si allí la mujer es diferente; don Antonio contesta: "-La mujer, en donde quiera, está hecha para que el hombre goce, pues” (201). Don Antonio, además, justifica la violencia contra estas: "Con su voluntad, sin su voluntad, por el mandato de Dios, la mujer es para el goce del macho" (201). Ya no estamos frente a un hacendando, sino frente a un mestizo cuyas concepciones son prácticamente las mismas, la reafirmación de la masculinidad a través de la sujeción de la mujer como objeto pasivo de placer, como lo ha señalado Castr-Klaren: "la posición de la mujer, por normatividad, es secundaria y cosificada" (1983: 55).

Además, Santiago no puede concebir a una mujer casada o blanca - Gudelia y Gabriela, la joven Hercilia- gozando de la sexualidad o asumiendo un rol activo; primero en el debate con el guitarrista Ambrosio dice: "—-La mujer sufre. Con lo que le hace el hombre, pues, sufre" (181) o con don Antonio: "Y ella sufre, llora" (201). Si bien no se puede negar que las escenas sexuales de Amor mundo están cargadas de violencia contra las mujeres, en su denuncia Santiago niega cualquier atisbo de placer femenino. El narrador muestra esa delgada línea ambigua entre el goce y el sufrimiento. Como lo señala Michael Kimmel: "The fact that the fear and sexual excitement often produce the same physiological responses may confuse men, who may mistake that fear for passion" (1990: 6). O la inversa, Santiago se muestra confundido al ver intacta a doña Gudelia luego de la orgía en el horno viejo: "Le extrañó que no cojeara, que no gimiera mientras andaba" (183).

Esta incapacidad no solo hace evidente las limitaciones de Arguedas para entender la subjetividad femenina y aceptar su sexualidad, como lo han señalado diferentes autores - Castro-Klaren, González o Silva Santisteban y Denegri-, sino es también un claro cuestionamiento a cómo se establecen los roles y jerarquías en las relaciones sexuales y de género entre hombres y mujeres en el mundo mestizo y blanco del Ande. ${ }^{11} \mathrm{O}$ desde otra perspectiva, Santiago, más

11 Silva-Santisteban y Denegri (2005) afirman que en su narrativa Arguedas solo pudo concebir a las mujeres en dos polos: "la virgen-madre (a quien se debe amar) y la mujer-puta (a quien se teme amar)". Sin embargo, en sus cartas aparece una tercera mujer: "La tercera mujer es la que puede gozar junto con el hombre con entera libertad, la que sabe cómo hacerse desear por el otro, y la que, para lograrlo, maneja conscientemente sus niveles de seducción, atracción y de fortaleza sexual...esta tercera mujer no posee un espacio simbólico en el imaginario de las relaciones entre géneros en nuestro autor". En la narrativa el rol activo y "El goce sexual es privativo de la loca de la comunidad, que es a su vez el objeto prohibido por excelencia” (Castro-Klaren 1983: 59). 
allá de los tabúes y la impronta religiosa que lo domina, está en la búsqueda de una masculinidad alternativa, como lo estuvo el Ernesto de Agua. El discurso de Arguedas intenta elaborar ese caos sexual que lleva dentro, pero también es una clara denuncia de la maquinaria viril patriarcal y su violencia sexual. Luego que doña Gudelia se siente "maldecida" por lo acontecido en el horno viejo; Santiago le replica: "iMaldecida no; abusada, pareada, emborrachada. Sólo el hombre asqueroso patea al cielo, también lo emborracha, alcanza con su mano embarrada al ángel” (183).

De otro lado, en el cierre del cuento, curiosamente Arguedas vuelve a perfilar la masculinidad no en el terreno de la virilidad sino de la hombría, en los valores sociales de ser hombre. Para don Antonio el sufrimiento del hombre está en su responsabilidad familiar, en el rol de proveedor que define su fortaleza como tal, es decir, en la performance de su hombría: "el hombre tiene que alimentar a la familia, a los hijos que ha hecho parir a la mujer. Y eso, también, es sufrimiento fuerte" (201). Aunque sin darse cuenta, muestra conflictos similares a los de Santiago. Para don Antonio el enamoramiento no existe cuando ya el hombre experimento el sexo: "sólo cuando estás muchacho, como tú, o menos quizás. Pero desde el momento en que tú ves cómo es la cosa de la mujer, la ilusión se acaba" (202). En el discurso de don Antonio se actualiza de un lado la condena cristiana del sexo y por otro propone la dualidad entre esposa/ prostituta y la forma de relacionarse con estas. Para don Antonio el goce solo se permite con una prostituta: "Porque con una puta tú haces todo, todo. Pagas tu platita. Y la conciencia limpia. Pa'eso es la puta” (202). En el matrimonio el goce es regido por la norma: "Una cosa es en la cama bendecida por el cura y por los padres de uno. Ahí con respeto, con delicadeza...Sí, el pior asco del hombre que es el sexo hace nacer al hijo [...] que uno quiere más que a los cielos y a las estrellas" (203). El sexo encuentra su redención en la procreación, en uno de los ejes de la virilidad, la capacidad reproductiva: "Pero yo [...] así como soy tengo un hijito [...] Se llama Marianito. Es mismo como el canto del chaucato y él mata todas las víboras que andan por mi cuerpo" (204). Nuevamente, la sexualidad es domesticada dentro de los linderos de su economía productiva: descendencia y familia. Sin embargo, la figura de don Antonio entra en crisis al condenar los hijos fuera del matrimonio, pues él mismo fue procreado en tal condición. La confesión vuelve a aparecer:

Primera vez...primera vez que se me sale decir. iYo no soy López, yo soy hijo de la porquería que hierve cuando cuerpo de hombre y de mujer no bendecidos se machucan por fuerza del infierno! Echan baba, como cuando se montan chancho y chancha. (204) 
En este caso la construcción de la identidad masculina se basa en el núcleo tradicional de la hombría basado en la honra familiar. Don Antonio y Santiago terminan encarnando una identidad masculino subalterna, ya sea por los conflictos sociales de una hombría dañada, deshonrada, o los conflictos sexuales de una virilidad igual de resentida. Don Antonio encuentra un símil con el indio Kutu de "Warma kuyay". Allí cuando Kutu desplaza la furia que siente por el gamonal violador azotando a los novillos de este. Don Antonio, al ver que uno de los toros muertos que transporta en su camión trata de introducir una rama bajo el rabo de la bestia: "-Así, como dicen que ese vejo le hizo a mi madre..." (204). Luego van por agua y se quiebra hasta el llanto: "El chofer de rostro erizado, de barba semicrecida, empezó a llorar primero, antes que el muchacho, pero sin detenerse" (205).

\section{A modo de conclusión}

Más allá de la mandatos cristianos contra el sexo y el tortuoso peregrinaje sexual de Santiago a lo largo de los cuentos de Amor mundo, parecen orbitar las preguntas: ¿es posible imaginar una forma de sexualidad masculina que se exprese sin violencia? ¿Los hombres pueden hallar modos alternativos para entender la triangulación entre mujeres, sexualidad y amor? Estas cuestiones resultan centrales en el contexto de un sistema social de haciendas andinas en el que las relaciones de dominación copan todos los espacios y prácticas cotidianas, incluidas las del sexo. En otras palabras, en los encuentros sexuales también se actualizan las jerarquías blanco/ indio, gamonal/ sirviente y, sobre todo, hombre/ mujer. Si bien como ha señalado la crítica recogida en este trabajo, la disociación entre el sexo, el erotismo, el placer y el amor marca el sino la narrativa de Arguedas - ya sea por las experiencias traumáticas de la niñez y la formación educativa religiosa-, en el discurso sexual de Amor mundo yace una denuncia muchas veces abierta de la violencia sexual propia de hombres blancos y mestizos.

Arguedas la mayoría de veces fracasa en la representación de la subjetividad femenina, pero alcanza sus mayores logros cuando le toca adentrarse en la densa subjetividad del género masculino. Sin embargo, esta inmersión en la identidad masculina es dolorosa. Santiago trata de llevar al entendimiento todo lo acontecido en sus experiencias sexuales y fracasa. Amor mundo no solo gira alrededor de los encuentros sexuales, el ars erótica foucaultiana, sino allí también está la scientia sexuales —el entendimiento racional de la que también habla el filósofo francés- a través de los diálogos sin resolución y el ritual de la confesión inservible y poco significativa. El niño adolescente no encuentra 
un modelo de masculinidad alternativo que armonice pacíficamente las relaciones con las mujeres, el amor y el erotismo. Por tanto, la construcción de la masculinidad del personaje central se muestra la mayoría de veces en crisis, a la vez que se opera un cuestionamiento de la masculinidad dominante de los hacendados como en Agua.

En ese sentido, Amor mundo, el último libro de cuentos de José María Arguedas, se localiza más cerca de Agua, el primero, en la incansable búsqueda de modelos alternativos de hombría y virilidad a los cuales adscribirse. En ese mundo mestizo y blanco de masculinidades patriarcales, Santiago, como el Ernesto de Agua, no encuentros modelos identitarios a seguir, y una vez más la masculinidad se ve frustrada en su continua actualización. La única sexualidad válida y posible modelo de virilidad la encuentra en un mundo indígena fuera de tiempo; en un ritual de orden reproductivo y economía comunitaria del cual tristemente no puede formar parte.

\section{Referencias bibliográficas}

ARGUEDAS, José María (1967). Amor mundo y todos los cuentos de José María Arguedas. Lima: Francisco Moncloa Editores.

ARGUEDAS, José María (1983). El zorro de arriba y el zorro de abajo. Lima: Editorial Horizonte.

ARGUEDAS, José María (1988). Agua. Lima: Editorial Horizonte.

BADINTER, Elisabeth (1993). XY. La identidad masculina. Bogotá: Grupo Editorial Norma.

BOURDIEU, Pierre (2000). La dominación masculina. Barcelona: Editorial Anagrama.

CASTRO-KLAREN, Sara (1983). “Crimen y castigo: Sexualidad en J. M. Arguedas”. En: Revista Iberoamericana 122; pp. 55-65.

CONELL, Raewyn (1997). "La organización social de la masculinidad”. En: Masculinidades. Poder y crisis. Teresa Valdés y José Olavarría (editores). Santiago: FLACSO; pp. 31-47.

DENEGRI, Francesca y Rocío Silva SANTISTEBAN (2005). “Lo que deseo es ser amado con pureza': sexo y horror en la obra de José María Arguedas”. En: Arguedas y el Perú de hoy. Carmen María Pinilla (editora). Lima: Sur Casa de Estudios del Socialismo; pp. 307-324.

DURÁN, David (2014). “Aquello que llaman 'tono de vida': mujer, economía y sexualidad en la narrativa de José María Arguedas". En: Arguedas. El Perú y las ciencias sociales: nuevas lecturas. Ricardo Cuenca y Ramón Pajuelo (editores). Lima: Instituto de Estudios Peruanos; pp. 109-130.

FOUCAULT, Michael (1998). Historia de la sexualidad I. La voluntad de saber. Madrid: Siglo XXI Editores. 
FULLER, Norma (2001). Masculinidades. Cambios y permanencias. Lima: Fondo Editorial de la PUCP.

GONZÁLEZ, Galo Francisco (1990). Amor y erotismo en la narrativa de José María Arguedas. Madrid: Editorial Pliegos.

HUAYTÁN MARTÍNEZ, Eduardo (2013). "Jugar el juego de los hombre. De mak'tillos a mak’tas en 'Los escoleros' de José María Arguedas”. En: Arguedas: la dinámica de los encuentros culturales. Cecilia Esparza, Miguel Giusti, Gabriela Núñez y otros (editores). Lima: Fondo Editorial de la PUCP; pp. 213-230.

JOHANSEN, Jørgen Dines (2004). “Literature, Pornography, and Libertine Education”. En: Orbis Litterarum 59; pp. 39-65.

KAUFMAN, Michael (1995). "Los hombres, el feminismo y las experiencias contradictorias del poder entre los hombres”. En: Género e identidad. Ensayos sobre lo femenino y lo masculino. Gabriela Arango, Magdalena León y Mara Viveros (compiladoras). Bogotá: Tercer mundo; pp. 123-146.

KIMMEL, Michael (1990) “Introduction: Guilty Pleasures-Pornography in Men's Lives”. En: Men Confront Porngraphy. Michael Kimmel (editor). New York: Crown Publishing Group, pp. 1-23.

LAMBRIGHT, Anne (2006). "El código de lo femenino en la narrativa de arguediana". En: José María Arguedas: hacia una poética migrante. Sergio R. Franco (editor). Pittsburg: Instituto Internacional de Literatura Iberoamericana-Universidad de Pittsburg; pp. 331-356.

MORALES ORTIZ, Gracias (2006). "Bajo la mirada del Arayá: análisis temático y discursivo de Amor mundo”. En: José María Arguedas: hacia una poética migrante. Sergio R. Franco (editor). Pittsburg: Instituto Internacional de Literatura IberoamericanaUniversidad de Pittsburg; pp. 357-377.

PINILLA, Carmen María (2011). “Apuntes biográficos de José María Arguedas”. En: José María Arguedas. Poética de un demonio feliz. Antonio Melis. Lima: Fondo Editorial del Congreso del Perú; pp. 3-50.

ROMERO, César (2013). “Un sexo desconocido confunde a esos'. Masculinidades y conflicto social en El zorro de arriba y el zorro de abajo". En: Arguedas: la dinámica de los encuentros culturales. Cecilia Esparza, Miguel Giusti, Gabriela Núñez y otros (editores). Lima: Fondo Editorial de la PUCP; pp. 185-202.

RUIZ BRAVO, Patricia y Eloy NEIRA (2001). "Enfrentados al patrón: una aproximación al estudio de las masculinidades en el medio rural peruano". En: Estudios culturales. Discursos, poderes y pulsiones. Santiago López Maguiña, Gonzalo Portocarrero y otros (editores). Lima: Red para el Desarrollo de las Ciencias Sociales en el Perú; pp. 211-231.

SAONA, Margarita (2013). "Raza, género y hombría en la obra temprana de Arguedas". En: Arguedas: la dinámica de los encuentros culturales. Cecilia Esparza, Miguel Giusti y otros (editores). Lima: Fondo Editorial de la PUCP; pp. 173-184. 